\title{
A Cross-sectional Survey of Job Stress Among Nurses Working at National Hospital Trauma Centre, Abuja, Nigeria
} \author{
Uduak-Enimose Onaghise ${ }^{3}$ \\ ${ }^{1}$ Department of Surgery, National Hospital Abuja, Abuja, Nigeria \\ ${ }^{2}$ Department of Obstetrics and Gynaecology, National Hospital Abuja, Abuja, Nigeria \\ ${ }^{3}$ Department of Nursing services, National Hospital Abuja, Abuja, Nigeria
}

Onyedika Godfrey Okoye ${ }^{1,}$, , Oluwole Olayemi Olaomi ${ }^{1}$, Uchenna Elizabeth Okoye ${ }^{2}$,

Email address:

dronyedika@yahoo.com (O. G. Okoye)

${ }^{*}$ Corresponding author

\section{To cite this article:}

Onyedika Godfrey Okoye, Oluwole Olayemi Olaomi, Uchenna Elizabeth Okoye, Uduak-Enimose Onaghise. A Cross-sectional Survey of Job Stress Among Nurses Working at National Hospital Trauma Centre, Abuja, Nigeria. European Journal of Clinical and Biomedical Sciences. Vol. 7, No. 2, 2021, pp. 27-32. doi: 10.11648/j.ejcbs.20210702.12

Received: April 16, 2021; Accepted: May 3, 2021; Published: May 14, 2021

\begin{abstract}
Background: Job stress is recognized world-wide as a major challenge to workers' health and their organizations. This study is intended to determine the work stress among nurses working in a Nigerian dedicated trauma centre. Methods: This is a cross-sectional study carried out at the trauma centre of a Nigerian tertiary institution from August to November 2017. All the nurses working in the trauma centre were included in the study. A structured, self administered questionnaire was used as the survey instrument. Data analysis was carried out using SPSS version 20.0. Results were presented in tables and figures. Results: A total of 80 nurses were enrolled in the survey with male to female ratio of 0.1 , mean age of $34 \pm 2.3$ and modal age group of 31-40years. The mean PSS was high (28.2). The major identified stressors were work load (50\%) and lack of consumables (22.5\%). Depression (2.5\%) was recorded only in female respondents. Despite the high PSS, none of the respondents has had any psychological counselling in the past year. Conclusion: The perceived stress scale among the studied population was high, with virtually no formal Psychological support. Efforts should be made to include regular psychological counseling in this group of people. A follow up study is strongly recommended.
\end{abstract}

Keywords: Job, Stress, Nurses, Trauma Centre

\section{Introduction}

Stress is an adaptive response, mediated by individual differences and psychological process that is a consequence of any external action, situation, or event that places excessive psychological or physical demands on a person [1]. Job stress is a condition arising from the interaction of people and their jobs and characterized by changes within people that force them to deviate from their normal functioning [2]. Job stress can further be defined as an individual's reactions to characteristics of the work environment that seem emotionally and physically threatening [3]. Work stress is recognized world-wide as a major challenge to workers' health and the healthiness of their organizations [4, 5]. World Health Organization has observed that stress is a worldwide epidemic because stress has recently been noted to be associated with $90 \%$ of visits to physicians [6]. In different researches it has become clear that about $30 \%$ of labours of developed countries have job stress disorder [7].

The nursing profession is known to be stressful throughout the world and has detrimental effects on the physical and psychological well-being of an individual's health [8,9]. Nurses play a pivotal role in and encompass the largest workforce in any health care institution; they act as direct caregivers who serve a hospital twenty-four hours a day, seven days a week. This gives nurses a unique perspective on both patient care and hospital operations [10]. Nursing, by virtue of its nature, is a profession subjected to a high degree of stress [11]. Occupational stress exists in all professions, but the nursing profession appears to experience more stress 
at work compared to other health-care workers [12-14]. Jobstress in the nursing profession has been a global problem with rates of $9.20-68.0 \%$ of nurses suffering from stress [15, 16]. Stressors contributing to the experience of work related stress, including poor supervision, conflict with peers and patients, high job demands [17, 18] and overtime [19] are all associated with one or more dimensions of stress.

Hospital workers must deal with life-threatening injuries and illnesses complicated by overwork, under-staffing, tight schedules, paper-work, intricate or malfunctioning equipment, complex hierarchies of authority and skills, dependent and demanding patients, and patient deaths, all of which are significant contributors to stress [20]. Furthermore, stressful aspects of the job such as overstretched bed allocation, long hours of work, stress of personal and family life and compromising standards when resources are short have been associated with psychological distress or depression among health care staff [21].

This study is intended to determine the work stress among nurses working in the National Trauma Centre, Abuja, Nigeria. This work in particular seeks to determine the level of work stress among the nurses, the major factors responsible for their work stress as well as elicit the perceived solution from the respondents.

\section{Methods}

\subsection{Study Design}

This is a cross sectional questionnaire based survey

\subsection{Setting}

This study was carried out at the National Trauma Centre of National Hospital Abuja. The hospital is located in the central business district, Abuja, Federal Capital Territory, Nigeria. National Hospital is a referral centre, strategically located to receive patients from the north central, from all parts of the country and beyond. The survey was done between August and November, 2017.

\subsection{Participants}

The study population for the survey research was all the nurses working in the Trauma Centre of National Hospital Abuja. A total of 80 nurses out of a population of about 100 nurses working in the centre consented and were enrolled into the survey. Informed consent was obtained in writing and was distributed alongside the survey instrument.

\subsection{Survey Instrument}

The study instrument was a structured questionnaire designed by the authors. The self -administered questionnaire was made up of four parts. The four parts include socio-demographic data, stressors/ stress level, management of stress each with six closed ended questions and perceived stress scale (PSS) which is typically made up of ten items [22]. Stress levels were classified using PSS into three groups: low for PSS 0-13, moderate for PSS 14-26 and high for PSS 27-40. The questionnaires were initially pretested on ten nurses before the final copies were produced.

\subsection{Statistical Methods}

Data recording, processing and analysis were done using statistical package for social sciences (SPSS) version 20.0. Chi Square test $\left(\mathrm{x}^{2}\right)$ and the student t- test were used to test the statistical differences for the qualitative and quantitative variables respectively. A value of $\mathrm{P}<0.05$ was considered significant. Frequency tables and charts were used where necessary to present the results.

\section{Results}

A total of 80 out of 100 questionnaires distributed, were correctly and completely filled and returned, representing a response rate of $80 \%$. The male to female ratio of the respondents was 0.1 with mean age of $34 \pm 2.3$. The most frequent age group was 31-40years followed by 21-30years which make up $47.3 \%$ and $25 \%$ respectively, while the least frequent age group was 51-60years old. No respondent was above 60 years of age. Table 1 .

Majority of the respondents (72.5\%) were married. Most of the respondents $(88.7 \%)$ possessed diploma and certificates in nursing while the remaining $11.3 \%$ had bachelor's degree. None of the respondents had masters or doctorate at the time of the survey. Slightly over half of the respondents $(51.3 \%)$ were $6-10$ years in their career as nurses, $23.7 \%$ were less than 5years, $15 \%$ were $11-15$ years and none was over 20years in the service. Table 1.

All the respondents noted that their job was stressful with majority (70\%) scoring high in PSS and the rest $(30 \%)$ scoring moderate. None scored low. The frequency of perceived stress among the respondents was monthly in close to half $(41.2 \%)$, weekly in $21.3 \%, 2-3$ monthly in $16 \%$, $4-$ 6 monthly in $12.5 \%$ and none beyond 6monthly. Almost half of the respondents $(47.5 \%)$ had taken sick off as a result of perceived stress in the previous year. All the respondents acknowledged that stress has negatively affected their job performance in the last year. However, only a very small proportion $(0.5 \%)$ had ever considered change of job as a result of stress. Table 2 .

Over half of the respondents $(67.5 \%)$ had never taken a daily short break at work, while $20 \%$ and $12.5 \%$ sparingly and sometimes respectively did. Majority of the respondents $(90 \%)$ were not regular in recreational activities while only $20 \%$ of the respondents had taken a vacation outside the city in the last one year. None of the respondents has received any formal psychological counseling in the last one year. Among the suggested adjustments to help reduce job stress, employment of more staff was on the top (43.8\%), followed by adequate consumables $(30 \%)$, and then improved staff welfare $(7.6 \%)$, better organizational set up and more breaks/vacations both in $6.2 \%$ of the respondents. Table 3 . 
Table 1. Socio-demographic Characteristics of the Respondents.

\begin{tabular}{lll}
\hline Variables & & Number of Respondents (\%) \\
\hline Age group (in years) & $\leq 20$ & $0(0.0)$ \\
& $21-30$ & $20(25.0)$ \\
& $31-40$ & $38(47.3)$ \\
& $41-50$ & $12(15.0)$ \\
& $51-60$ & $10(12.5)$ \\
Mean Age & $>60$ & $0(0.0)$ \\
Sex & $34 \pm 2.3$ & \\
& Male & $08(10.0)$ \\
Marital Status & Female & $72(90.0)$ \\
Highest Educational Qualification & Single & $22(27.5)$ \\
& Married & $58(72.5)$ \\
Number of Years of Service & Diploma/Certificate & $71(88.7)$ \\
& Bachelor & $09(11.3)$ \\
& Masters/ PhD & $00(00.0)$ \\
& $\leq 5$ & $19(23.7)$ \\
& $6-10$ & $41(51.3)$ \\
& $11-15$ & $12(15.0)$ \\
\hline
\end{tabular}

Table 2. Perceived Level of Stress of the Respondents.

\begin{tabular}{lll}
\hline Variables & & Number of Respondents (\%) \\
\hline My job is stressful & Yes & $80(100.0)$ \\
PSS & No & $00(00.0)$ \\
& Low & $00(00.0)$ \\
& Moderate & $24(30.0)$ \\
Frequency of Perceived Stress & High & $56(70.0)$ \\
& Mean Score & 28.2 \\
& Weekly & $17(21.3)$ \\
& Monthly & $33(41.2)$ \\
Sick off as a result of stress in the last one year & $2-3$ monthly & $16(20.0)$ \\
& $4-6$ monthly & $10(12.5)$ \\
Stress has affected my work performance negatively in the last one year & $>6$ monthly & $04(5.0)$ \\
& Yes & $38(47.5)$ \\
I have considered change of job due to stress & Yes & $42(52.5)$ \\
& No & $80(100.0)$ \\
& Yes & $00(00.0)$ \\
\end{tabular}

Table 3. Coping Mechanisms and Adjustments among the Respondents

\begin{tabular}{|c|c|c|}
\hline Variables & & Number of Respondents (\%) \\
\hline \multirow[t]{4}{*}{ Daily short break at work } & Always & $00(00.0)$ \\
\hline & Sometimes & $10(12.5)$ \\
\hline & Sparingly & $16(20.0)$ \\
\hline & Never & $54(67.5)$ \\
\hline \multirow[t]{2}{*}{ Engagement in regular recreational activities } & Yes & $8(10.0)$ \\
\hline & No & $72(90.0)$ \\
\hline \multirow[t]{2}{*}{ Vacation outside Abuja in the last one year } & Yes & $16(20.0)$ \\
\hline & No Answer & $04(05.0)$ \\
\hline \multirow[t]{2}{*}{ Formal Psychological Counselling in the last one year } & Yes & $00(00.0)$ \\
\hline & No & $80(100.0)$ \\
\hline \multirow[t]{5}{*}{ Suggested Adjustments to reduce stress level } & Shorter duration of Shift & $05(06.2)$ \\
\hline & Employment of more staff & $35(43.8)$ \\
\hline & Improve Staff Welfare & $06(07.6)$ \\
\hline & Better organizational set up & $05(06.2)$ \\
\hline & Adequate consumables & $24(30.0)$ \\
\hline
\end{tabular}

In terms of predominant symptoms of stress among the respondents, over half (53.7\%) reported body aches, followed by headache $(15 \%)$, exhaustion $(13.7 \%)$, nervousness $(8.7 \%)$, agitation $(6.2 \%)$ and depression $(2.5 \%)$. More proportion of 
female nurses reported body aches (55.5\% vs $37.5 \%)$ and depression $(2.5 \%$ vs $0 \%)$ than their male counterparts. This observed difference is however not statistically significant $(\mathrm{p}=0.369)$. Figure 1.

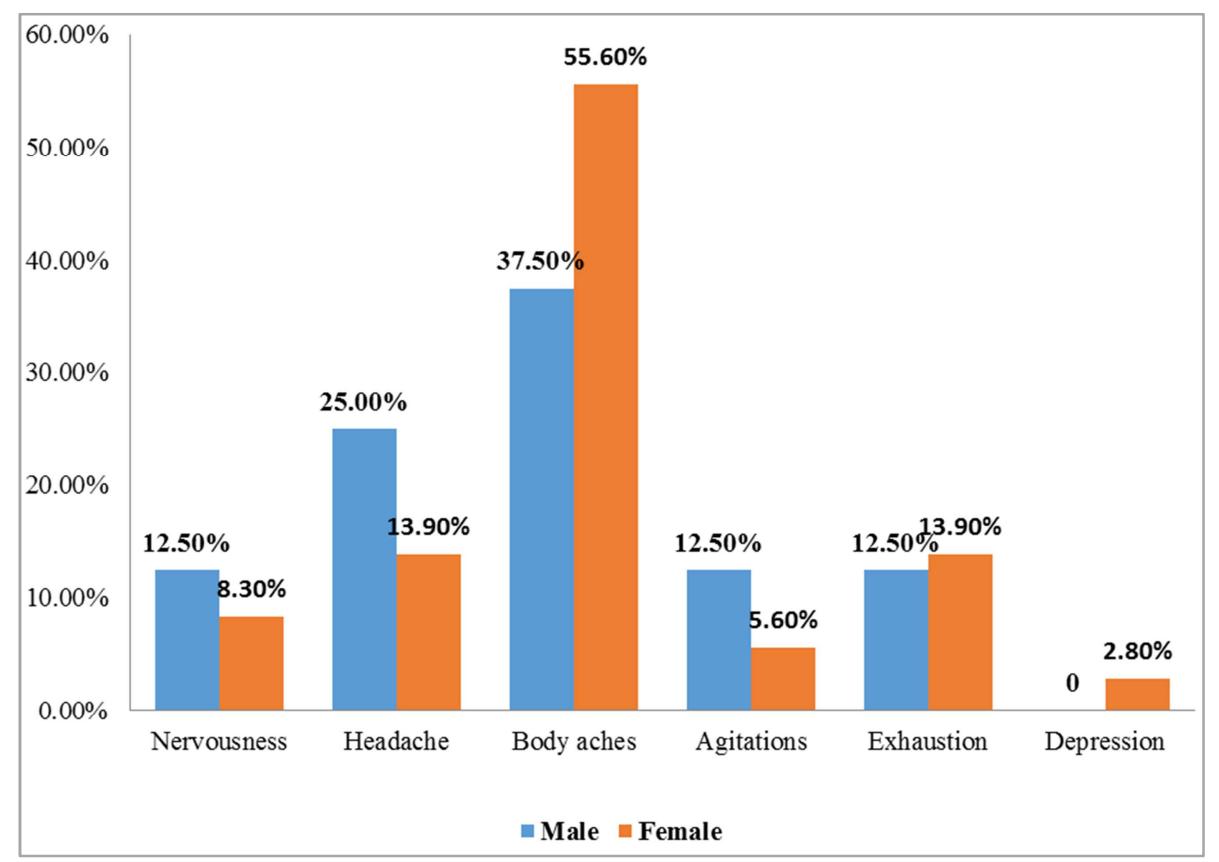

Figure 1. Predominant Features of Stress by Gender.

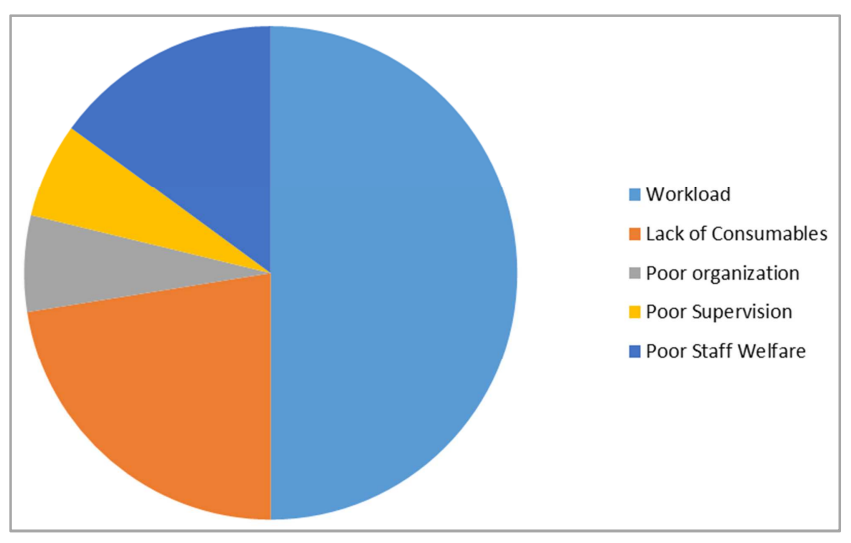

Figure 2. Key Stressors among the Respondents.

Figure 2 revealed that half of the respondents $(50 \%)$ believed that workload is the key factor contributing to stress. Others reported lack of consumables (22.5\%), poor staff welfare (15\%) and poor supervision/ poor organization in $6.2 \%$ of cases.

\section{Discussion}

A hundred questionnaires were distributed and eighty were adequately completed and returned giving a response rate of $80 \%$. This is a good response considering the busy population of nurses assessed in this study. Majority of the nurses were females with a male to female ratio of 0.1 . This is not surprising as nursing profession is predominantly a female profession globally. This is similar to other studies around the world [12, 13, 19, 23-26]. The modal age group of 31-40 years represent vibrant young adults suited for the busy trauma centre. Age may have been considered in the selection criteria of nurses posted to trauma centre to ensure that young and strong men and women were deployed in this busy part of the hospital. This age group is similar to works done elsewhere [27] but differs in other places where most respondents were in their mid forties $[25,26]$. Only very few respondents $(12.5 \%)$ were above 50years. These are probably the ones in the administration or supervisory role.

Majority of the respondents are married $(72.5 \%)$. This is important as domestic issues associated with marriage may have some contribution on job stress. This is also seen in other places $[25,26]$. All the respondents are qualified nurses with fairly uniform qualification where over $85 \%$ have nursing diploma/ certificate. This is commendable and may have impact on the coping mechanisms. This finding sharply contrasts with an Iranian study where majority of the nurses (80\%) had bachelor's degree [24]. The majority of the respondents have 6-10years and less than 5 years working experience as a nurse. None of the respondents is over 20years in the profession. This further affirms the relatively young age of the studied population.

All the respondents agree that their job is stressful. This is a general notion in different regions of the world. A recent study conducted on surgical trainees in Nigeria affirms that working in a trauma centre is quite stressful [28]. The average PSS of 28.2 which signifies high perceived stress level is not surprising in a trauma centre which is usually a very busy emergency point. This high stress level has been found in similar studies in other parts of the world [29-32]. In contrast, low to medium stress level have been reported in some other climes [24, 27, 33]. The frequency of perceived stress which is mostly monthly among the studied group 
further collaborates the severity of stress in this group. The number of sick off as a result of perceived stress is high $(47.5 \%)$. This is definitely not good for the centre and would affect job performance. This negative effect on job performance was chorused by all the respondents. This finding is collaborated by other studies [23, 32]. Only very few respondents had considered change of job despite the level of stress. This is probably because of fear of getting a better job when one looks at the unemployment rate in the society.

The large proportion of respondents who neither take breaks, indulge in regular exercise and vacation is not encouraging. It is rather disappointing to see this finding among health workers. It is possible that this lack of physical activity/vacation may indirectly contribute to their level of stress. Surprisingly, despite the recorded high level of stress in this studied group, none of them has had any formal psychological counseling. This is probably because the institution has not specifically recognized job stress as a significant entity that can affect the job performance of nurses. Regular psychological counseling has been advised for nurses [34]. Workload and lack of consumables were identified as major key factors contributing to their stress (stressors). This is probably a general trend in many government hospitals in developing economy. This is also in line with some findings in Europe where workload and resources were highlighted [26, 35]. Similarly, the respondents' suggestions of employment of more staff and provision of adequate consumables are in line with the above findings. Interestingly, interpersonal conflicts were not reported, in contrast to some other studies.

The predominant features of stress among the studied population were body aches and headache. These are non specific features of stress. Features of stress are highly variable among individuals. It is interesting to note that only very tiny proportion $(2.5 \%)$ of the respondents reported features of depression, in contrast to findings in so many studies from many centres around the world where depression was seen in $35 \%$ to $51 \%$ of cases [36-38]. It is noted that body aches were more and depression was found only among the female nurses. However, this observed difference is not statistically significant. This finding is not easy to explain but may be linked to the perceived vulnerability of female sex to stress especially when their domestic roles are added. This seems to be true in this study where majority of the respondents are married. Similar combination of factors of work, marriage and children have been noted in other studies around the world [39, 40].

\section{Conclusion}

The perceived stress scale among the nurses working in the National Hospital Trauma Centre, Abuja, Nigeria was high, with virtually no formal Psychological support. The results show that nursing profession is associated with a significant high level of job stress, more so when a busy section of the institution is assessed. This finding can easily be extrapolated to other medical and health workers working in this busy unit. Efforts should be made to include regular psychological counseling in this group of people. Engaging the employees on some of the modifiable contributory factors will go a long way in finding solution to this inevitable challenge. We strongly recommend a follow up study on this topic.

\section{Conflict of Interest}

The authors declare that they have no competing interests.

\section{References}

[1] Ivancevich, J. M., Matteson, M. T. \& Preston, C. (1982). Occupational stress, Type A behavior and physical well-being. Academy of Management Journal, 25, 373-391.

[2] Luthans, F. (2002). Organizational behavior (9th ed.). Boston: McGraw-Hill Irwin.

[3] Jamal, M. (2005). Burnout among Canadian and Chinese employees: A cross-cultural study. European Management Review, 2, 224-230.

[4] ILO (1986) International Labour Organization Psychosocial Factors at Work: Recognition and Control. Occupational Safety and Health Series. International Labour Office, Geneva 56.

[5] ILO (1992) International Labour Organization Preventing Stress at Work. Conditions of Work Digest. International Labour Office, Geneva 11.

[6] Akinboye J, Akinboye D, Adeyemo D (2002) Coping with Stress in Life and Work place. Stirling-Horden Publishers [Nig] Ltd Ibadan, Nigeria.

[7] Aghilinejad M, Mohammadi S, Afkari M, Abbaszade Dizaji R. Surveying the association between occupational stress and mental health, personality and life stressful events in Tehran police officers. Pejouhesh. 2007; 31 (4): 355-60.

[8] Onasoga Olayinka A, Ogbebor Sarah Osamudiamen, Ojo AA (2013) Occupational stress management among nurses in selected hospital in Benin city, Edo state, Nigeria. Euro J Exp Biol 3: 473-81.

[9] Golshiri P, Pourabdian S, Najimi A, Zadeh HM, Hasheminia J. Job stress and its relationship with the level of secretory IgA in saliva: a comparison between nurses working in emergency wards and hospital clerks. J Pak Med Assoc. 2012; 62 (3 Suppl 2): S26-S30].

[10] FDRE MOH. Nursing Care Practice Standards Version 2. Addis Ababa, Ethiopia: FDRE MOH (Federal Democratic republic of Ethiopia Ministry of Health); 2011.

[11] Saini R, Kaur S, Das K. Assessment of stress and burnout among intensive care nurses at a tertiary care hospital. J Mental Health Hum Behav. 2011; 16 (1): 43-48.

[12] Moustaka E, Constantinidis T. Sources and effects of Workrelated stress in nursing. Health Sci J. 2010; 4: 210-16.

[13] Sharifah ZSY, Afiq IM, Siti SD. Stress and its associated factors amongst ward nurses in a public hospital Kuala Lumpur. Malaysian J. Public Health Med. 2011; 11 (1): 78-85. 
[14] Wu H, Chi T, Chen L. Occupational stress among hospital nurses: cross sectional survey. J Adv Nurs. 2010; 66 (3): 627 34.

[15] Sudhaker C, Gomes L. Stress, coping strategies and the job quality index of nurses working in selected multispecialty hospitals-towards human.

[16] Hajjar B Al. Occupational stress among hospital nurses in Gaza-Palestine. University of Manchester; 2013. p. 1-289. Available from: https://www.escholar.manchester.ac.uk/api/datastream?public ation Pid=uk-ac-man-scw: $189872 \&$ datastreamId=fulltext.pdf.

[17] Chayu, T.; Kreitler, S. Burnout in nephrology nurses in Israel. Nephrol. Nurs. J. 2011, 38, 65-78.

[18] Hayter, M. Burnout and AIDS care related factors in HIV community nurse specialists. J. Adv. Nurs. 1999, 29, 984-993.

[19] Garrosa, E.; Rainho, C.; Moreno-Jimenez, B.; Monteiro, M. J. The relationship between job stressors, hardy personality, coping resources and burnout in a sample of nurses: A correlational study at two time points. Int. J. Nurs. Stud. 2010, 47, 205-215.

[20] Guide-lines for protecting the Health and Safety of Health Care Worker. DHHS (NIOSH) Publication No 88-119; 1988 Sept.

[21] Burbeck R, Coomber S, Robinson SM, Todd C. Occupational stress in consultants in accident and emergency medicine: a national survey of levels of stress at work. Emerg Med J 2002; 19: $234-8$.

[22] Cohen S, Kamarck T, Mermelstein R. A global measure of perceived stress. Journal of Health and Social Behaviour 1983; 24: $286-396$

[23] Jennings BM. Work stress and burn out among nurses: role of the work environment and working conditions In: Hughes RG, editor. Patient Safety and Quality: An Evidence-Based Handbook for Nurses. Rockville (MD): Agency for Healthcare Research and Quality (US); 2008.

[24] Najimi A, Goudarzi AM, Sharifirad G. Causes of job stress in nurses: a cross-sectional study. Iran J Nurs Midwifery Res 2012; 17 (4): 301-305

[25] Gottlieb BH, Kelloway EK, Martin-Matthews A. Predictors of work-family conflict, stress, and job satisfaction among nurses. Can J Nurs Res 1996; 28 (2): 99-117.

[26] Bryant C, Fairbrother G, Fenton P. The relative influence of personal and workplace descriptors on stress. Brit J Nurs 2000; 9 (13): 876-80.
[27] Sathiya N, Ruwaidha R, Nusrath FS, Fathima F, Gomathy T, Shailendra HK. Perceived Stress Levels And its Sources Among Doctors and Nurses Working In A Tertiary Care Teaching Hospital, Kancheepuram, Tamil Nadu. Ntl J Community Med 2016; 7 (7): 603-608.

[28] Okoye O, Ameh E, Ojo E. Perception and attitude of surgical trainees in Nigeria to trauma care. Surg Res Pract. 2021 Jan 30; 2021: 6584813. doi: 10.1155/2021/6584813.

[29] Laschinger HK, Almost J, Purdy N, et al. Predictors of nurse managers' health in Canadian restructured health settings. Nurs Leadershp 2004; 17 (4): 88-105.

[30] Menzies IE. Nurses under stress. Int Nurs Rev 1960; 7: 9-16.

[31] Ayon MA. The Effects of Holistic Coping Strategies on Perceived Stress and Absenteeism in Hospital Nurses. ScholarWorks 2014 Dec.

[32] Rajeswari H, Sreelekha B. Stress among nurses in a tertiary care hospital. Int J Ind Psychology 2016; 3 (2): 154-164.

[33] Gupta A, Koolwal GD, Gehlot S. Study of perceived stress and emotional intelligence among $1 \mathrm{st}$ year medical undergraduates in India. J Contemp Med Edu 2014; 2 (1): 6367.

[34] Hatcher S, Laschinger HKS. Staff nurses' perceptions of job empowerment and level of burnout: a test of Kanter's theory of structural power in organizations. Can J Nurs Adm 1996; 9 (2): 74-94.

[35] Chatzigianni D, Tsounis A, Markopoulos N, Sarafis P. Occupational stress experienced by nurses working in a Greek Regional Hospital: A cross-sectional study. Iran J Nurs Midwifery Res 2018; 23: 450-7.

[36] Cheung T, Yip PS. Depression, anxiety and symptoms of stress among Hong Kong nurses: A cross-sectional study. Int J Environ Res Public Health 2015; 12: 11072-100.

[37] Maharaj S, Lees T, Lal S. Prevalence and risk factors of depression, anxiety, and stress in a cohort of Australian nurses. Int J Environ Res Public Health 2018; 16: 61.

[38] Carayon P, Gurses AP. Nursing Workload and Patient SafetyA Human Factors Engineering Perspective. In: Hughes RG, editor. Patient Safety and Quality: An Evidence-Based Handbook for Nurses. Rockville (MD): Agency for Healthcare Research and Quality (US); 2008.

[39] Woods NF. Employment, family roles, and mental ill health in young married women. Nurs Res 1985; 34: 4-10.

[40] Haw MA. Women, work and stress: A review and agenda for the future. J Health Soc Behav 1982; 23: 132-44. 